\title{
Effects of Social Support on Post-Traumatic Stress of Firefighters
}

\author{
Sung-Sim Lee ${ }^{1}$, Sookyoung Jeong ${ }^{2}$ and Young-Soon Choi ${ }^{3 *}$ \\ ${ }^{1,2}$ Dept. of Nursing, Saekyung College, 197, Hasong-ro, Yeongwol-eup, Yeongwol- \\ gun, Gangwon-do, Republic of Korea \\ ${ }^{3}$ Dept. of Nursing, Kangwon National University, Samcheck-si, Gangwon-do, 25949, \\ Republic of Korea

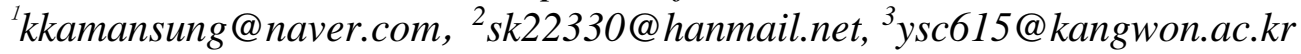

\begin{abstract}
This study was attempted to provide basic data on mental health by identifying factors affecting the post-traumatic stress of firefighting officers. The data collection was conducted from October 1, 2018 to October 31, 2018, with the consent of the target person and the questionnaire was conducted. The number of participants used in the final analysis was 138. The questionnaire consisted of demographic characteristics, social support and post-traumatic stress. The collected data were analyzed using SPSS 21.0 statistical program using descriptive statistics, t-test, ANOVA, Pearson's correlation, and Multiplier regression. The results of this study showed that the difference in social support according to general characteristics was the result of work experience, subjective health state and in post-traumatic stress, statistically significant differences were shown in subjective health state, feeling the need for counseling, and mental health service experience. Post-traumatic stress showed a static negative correlation with emotional support, information support, material support, and evaluation support. But social support showed a positive correlation with all of the subdomain.
\end{abstract}

Keywords: Firefighter, Social support, Post-traumatic stress, Health

\section{Introduction}

Firefighters are under a lot of stress due to poor working environment and shift work compared to general public employees. In addition, there is always anxiety that you can do it because of your colleagues' injuries or turnover in the sense of duty and tension about saving people's lives in fire, rescue, emergency activities, and disaster field activities, it is a cause of health threat due to the adverse effects of psychological and physical pain experienced in extreme situations, and it is also negatively affected by the efficiency of work [1].

Firefighters are also known to be at high risk for mental aftereffects such as depression and post-traumatic stress disorder (PTSD) compared to the general public due to repeated exposure to trauma cases [2].

In the case of firefighting officers in developed countries, $17 \%$ in Canada, $18 \%$ in the United States, and $17.7 \%$ in Japan have the prevalence of post-traumatic stress disorder, In the recent survey, 36.5 percent of Korean firefighters are at high risk for post-traumatic stress disorder (Fire and Emergency Management Agency), which is higher than other countries, and the seriousness is emerging as a social problem [2]. Post-traumatic stress disorder is a disorder that

Article history:

Received (June 13, 2019), Review Result (July 26, 2019), Accepted (September 8, 2019) 
occurs when you experience severe stress from trauma. In other words, after experiencing a serious trauma, it is a disorder that occurs after trauma exposure, repeatedly experiencing the event, avoiding the stimulus associated with the event continuously, and showing an increase in paralysis and arousal [3]. And with this condition, depression, anxiety, loss of interest, difficulty in concentration in everyday life, indifference in interpersonal relationships, surprise, and stupid attitude, and sleep disorders and irritation are shown. And if there are victims in trauma cases, they may have guilt, shame, and rejection of surviving alone [3].

A study on personal factors associated with post-traumatic stress disorder has a relationship with depression, anxiety, and emotional disorders [4]. The past experience of treatment for psychological disorders, and the degree of experience of post-traumatic stress disorder may vary depending on neurosis [5].

Social support is an environmental variable that means a variety of positive resources, such as love, recognition, material help, and information, which can be obtained from others through social relationships, and is an environmental variable that plays an important role in human healthy development and adaptation by fully satisfying the basic social needs of people and forming control over the environment [6][7]. Cobb stated that he believed that he was loved, respected, valued by others, and believed to be a member of a communication network [7].

Those who receive social support are more adaptable to overcome negative stress, while those who do not receive social support are more likely to be depressed due to reduced adaptability [8]. Social support can protect you from the emotional and physical symptoms of stress and relieve your symptoms [9]. In general, the appropriateness of social support is the most important analysis in the sources of support (source) and type (type) [10][11]. The source of social support for post-traumatic stress of firefighting officers is family, friends, colleagues, society, religious organizations, and social organizations [12].

There is a previous study on social support among the factors that alleviate post-traumatic stress of firefighting officers [9][11][13], but there is a lack of research on how the support target affects social support.

This study confirms the social support of firefighting officers and the degree of posttraumatic stress, and confirms the relationship between social support and post-traumatic stress. In addition, we conducted this study to identify factors affecting post-traumatic stress and to use it as basic data to improve the mental health of firefighting officers and to help them find ways to cope with stress.

\section{Research method}

\subsection{Research design}

This study was a descriptive research using structured questionnaires to investigate the effect of social support on the post-traumatic stress of firefighter.

\subsection{Research subject}

This study was conducted for fire fighter in Y city in Gangwondo Province. The purpose of this research was understood and it was conveniently extracted to those who voluntarily agreed to participate in the research. The number of samples was calculated by using G*Power 3.1.5 program for multiple regression analysis, the significance level was calculated as .05, the power was .95 , the effect size was .15, and the final sample size was 138 people. A total of 150 copies were distributed in consideration of the number of dropouts, and 140 copies were collected. 
Among them, 138 data were used for the final analysis except for 2 cases where the response was insufficient.

\subsection{Research tools}

\subsubsection{Social support:}

Social support tools developed by Park were used [14]. The tool consists of the subdomain of emotional support, information support, material support, and evaluative support. A total of 25 questions, a 5-point Likert scale, means that the higher the score, the higher the social support. The Cronbach's value in the study of Park was .95, and the Cronbach's value in this study was .98 .

\subsubsection{Post-traumatic stress:}

The Impact of Evant Scale (Impact of Evant Scale: IES) developed by Horowitz [15], which was used the Impact of Evant Scale Revision Korean (IES-R-K) [16]. The tool consists of the subdomain of over-awakening, avoidance invasion, sleep disorders, emotional paralysis, and dissociation symptoms. A total of 22 questions, a 5-point Likert scale, means that the higher the score, the higher the post-traumatic stress. The Cronbach's value in the study of Eun was .83, and the Cronbach's value in this study was .96.

\subsection{Data collection}

Data collection was made through the one-to-one interview by each individual with a researcher and 3 research assistants, who were trained in advance, from October 1, 2018, to October 31. A structured questionnaire was used in subjects with a written consent of participating in the research. A total of 150 copies were distributed in consideration of the number of dropouts, and 140 copies were collected. Among them, 138 data were used for the final analysis except for 2 cases where the response was insufficient.

\subsection{Data analysis}

The collected data are analyzed using the SPSS 21.0 program as follows. Social support and post-traumatic stress level according to the demographic characteristics of the subjects was analyzed with descriptive statistics, t-test, ANOVA, and post-test were used for Scheff's test. The correlations between social support and post-traumatic stress were analyzed using Pearson's correlation. The effects of the post-traumatic stress were analyzed by multiple regression.

\section{Research results}

\subsection{Difference in social support, post-traumatic stress of according to general characteristics}

The difference between social support and post-traumatic stress according to general characteristics, Social support is based on the work experience $(\mathrm{F}=3.07, \mathrm{p}<05)$, subjective health state $(\mathrm{F}=7.45, \mathrm{p}<001)$, In post-traumatic stress, statistically significant differences were shown in subjective health state $(\mathrm{F}=4.43, \mathrm{p}<05)$, feeling the need for counseling and treatment $(\mathrm{t}=3.31, \mathrm{p}<001)$, and mental health service experience $(\mathrm{t}=3.30, \mathrm{p}<05)$ [Table 1]. 
Table 1. Difference in social support, post-traumatic stress of according to general characteristics $(\mathrm{N}=138)$

\begin{tabular}{|c|c|c|c|c|c|c|}
\hline \multirow[b]{2}{*}{ Characteristics } & \multirow[b]{2}{*}{ Categories } & \multirow[b]{2}{*}{$\mathrm{n}(\%)$} & \multicolumn{2}{|c|}{ Social support } & \multicolumn{2}{|c|}{ Post-traumatic stress } \\
\hline & & & $\mathrm{M} \pm \mathrm{SD}$ & $\begin{array}{l}\mathrm{t} / \mathrm{F}(p), \\
\text { Scheffe }\end{array}$ & $\mathrm{M} \pm \mathrm{SD}$ & $\begin{array}{l}\mathrm{t} / \mathrm{F}(p) \\
\text { Scheffe }\end{array}$ \\
\hline \multirow{2}{*}{ Gender } & Male & 126(91.3) & $91.16 \pm 17.64$ & \multirow{2}{*}{$0.56(.570)$} & $36.50 \pm 14.71$ & \multirow{2}{*}{$0.50(.618)$} \\
\hline & Female & $12(8.7)$ & $88.16 \pm 15.16$ & & $34.33 \pm 9.14$ & \\
\hline \multirow{4}{*}{ Age(year) } & $20 \sim 29$ & $18(13.0)$ & $91.33 \pm 16.94$ & \multirow{4}{*}{$0.46(.708)$} & $37.55 \pm 14.87$ & \multirow{4}{*}{$0.11(.951)$} \\
\hline & $30 \sim 39$ & $51(37.0)$ & $92.62 \pm 16.61$ & & $36.60 \pm 15.07$ & \\
\hline & $40 \sim 49$ & $57(41.3)$ & $90.17 \pm 17.33$ & & $35.52 \pm 12.69$ & \\
\hline & $50 \sim 59$ & $12(8.7)$ & $86.41 \pm 22.60$ & & $36.91 \pm 18.66$ & \\
\hline \multirow{4}{*}{ Education } & $\begin{array}{l}\text { High } \\
\text { school }\end{array}$ & $34(24.6)$ & $88.73 \pm 18.84$ & \multirow{4}{*}{$0.34(.791)$} & $36.44 \pm 15.01$ & \multirow{4}{*}{$0.12(.943)$} \\
\hline & College & $32(23.2)$ & $90.53 \pm 16.84$ & & $36.25 \pm 16.05$ & \\
\hline & University & $70(50.7)$ & $92.24 \pm 17.23$ & & $36.10 \pm 13.45$ & \\
\hline & $\begin{array}{l}\text { Graduate } \\
\text { school }\end{array}$ & $2(1.4)$ & $87.00 \pm 15.55$ & & $42.50 \pm 6.36$ & \\
\hline \multirow{5}{*}{$\begin{array}{l}\text { Total work } \\
\text { experience } \\
\text { (years) }\end{array}$} & $<5 \mathrm{yra}$ & $40(29.1)$ & $88.75 \pm 14.82$ & \multirow{5}{*}{$\begin{array}{c}3.07(.018) \\
b>c>a>d>e\end{array}$} & $37.70 \pm 13.67$ & \multirow{5}{*}{$1.34(.258)$} \\
\hline & $\begin{array}{c}6 y r \sim 10 y r \\
b\end{array}$ & $33(23.9)$ & $98.63 \pm 17.76$ & & $38.00 \pm 17.01$ & \\
\hline & $\begin{array}{l}11 \mathrm{yr} \sim \\
15 \mathrm{yr} \mathrm{c}\end{array}$ & $21(15.2)$ & $93.66 \pm 16.55$ & & $34.61 \pm 10.60$ & \\
\hline & $\begin{array}{l}16 \mathrm{yr} \sim \\
20 \mathrm{yr} \mathrm{d}\end{array}$ & $10(7.2)$ & $87.30 \pm 19.08$ & & $27.10 \pm 6.13$ & \\
\hline & $>20 y r$ e & $34(24.6)$ & $85.29 \pm 17.93$ & & $29.65 \pm 12.06$ & \\
\hline \multirow{5}{*}{$\begin{array}{l}\text { Subjective } \\
\text { health state }\end{array}$} & $\begin{array}{c}\text { Very } \\
\text { healthy a }\end{array}$ & $20(14.5)$ & $103.05 \pm 15.67$ & \multirow{5}{*}{$\begin{array}{c}7.45(<.001) \\
\mathrm{a}, \mathrm{b}>\mathrm{c}, \mathrm{d}>\mathrm{e}\end{array}$} & $29.65 \pm 12.06$ & \multirow{5}{*}{$\begin{array}{l}4.43(.002) \\
e>c, d>a, b\end{array}$} \\
\hline & $\begin{array}{l}\text { General } \\
\text { health } b\end{array}$ & $66(47.8)$ & $93.39 \pm 16.23$ & & $34.10 \pm 12.38$ & \\
\hline & Usually c & $33(23.9)$ & $84.24 \pm 16.91$ & & $39.87 \pm 16.20$ & \\
\hline & $\begin{array}{c}\text { Slight } \\
\text { disease d }\end{array}$ & $17(12.3)$ & $83.47 \pm 13.55$ & & $43.41 \pm 14.45$ & \\
\hline & $\begin{array}{l}\text { Serious } \\
\text { disease e }\end{array}$ & $2(1.4)$ & $60.50 \pm 6.36$ & & $56.50 \pm 16.23$ & \\
\hline \multirow{2}{*}{$\begin{array}{l}\text { Consider } \\
\text { counseling, } \\
\text { treatment help }\end{array}$} & Yes & $22(15.9)$ & $88.40 \pm 16.87$ & \multirow[b]{2}{*}{$-0.73(.465)$} & $45.27 \pm 16.21$ & \multirow[b]{2}{*}{$3.31(.001)$} \\
\hline & No & $116(84.1)$ & $91.37 \pm 17.55$ & & $34.61 \pm 13.32$ & \\
\hline \multirow{2}{*}{$\begin{array}{l}\text { Experience in } \\
\text { using mental } \\
\text { health services }\end{array}$} & Yes & $7(5.1)$ & $85.85 \pm 23.81$ & \multirow[b]{2}{*}{$-0.78(.433)$} & $51.71 \pm 9.77$ & \multirow[b]{2}{*}{$3.00(.003)$} \\
\hline & No & 131(94.9) & $91.17 \pm 17.09$ & & $35.48 \pm 14.06$ & \\
\hline
\end{tabular}

\subsection{Level of social support and post-traumatic stress}


The post-traumatic stress was $36.31 \pm 14.30$ on the scale of 110 points. The level of social support was $90.90 \pm 17.41$ on the scale of 125 , in the subdomain, emotional support was $25.78 \pm 5.09$ on the scale of 35 , informative support was $22.13 \pm 4.40$ on the scale of 30 , material support was $20.79 \pm 4.49$ on the scale of 30 , and evaluative support was $22.24 \pm 4.45$ on the scale of 30 points [Table 2].

Table 2. Level of social support and post-traumatic stress $(\mathrm{N}=138)$

\begin{tabular}{ccc}
\hline Variable & Range & $\mathrm{M} \pm \mathrm{SD}$ \\
\hline Post-traumatic stress & $22 \sim 110$ & $36.31 \pm 14.30$ \\
Social support & $25 \sim 125$ & $90.90 \pm 17.41$ \\
Emotional support & $7 \sim 35$ & $25.78 \pm 5.09$ \\
Informative support & $6 \sim 30$ & $22.13 \pm 4.40$ \\
Material support & $6 \sim 30$ & $20.79 \pm 4.49$ \\
Evaluative support & $6 \sim 30$ & $22.24 \pm 4.45$ \\
\hline
\end{tabular}

\section{Discussion}

This study was conducted to identify the social support of firefighting officers and the degree of post-traumatic stress in the $\mathrm{C}$ and $\mathrm{Y}$-gun firefighting officers in Gangwon-do, and to identify the factors affecting their relevance and post-traumatic stress. Firefighters are experiencing constant physical and mental stress, especially traumatic events, and are frequently exposed to traumatic events such as terrible sites, which is highly dangerous to post-traumatic stress disorder be reported [17].

The study found that the social support of firefighters was $90.90 \pm 17.41$ on a scale of 125 , and the difference in social support based on general characteristics was significant in working experience $(\mathrm{F}=3.07, \mathrm{p}<05)$, subjective health condition $(\mathrm{F}=7.45, \mathrm{p}<001)$. One of the preventions that generally prevent stress-related diseases is social support (social support). Social support helps overcome the painful feelings of trauma [18], and reports that social support is a major factor in reducing the stress of firefighters [19].

Post-traumatic stress has a negative correlation with social support $(r=.290, p<001)$, and which is the subdomains of social support $(r=.301, \mathrm{p}<001)$ is emotional support $(\mathrm{r}=.240, \mathrm{p}<001)$, information support $(\mathrm{r}=.301, \mathrm{p}<001)$, material support $(\mathrm{r}=.269, \mathrm{p}<001)$, and evaluative support $(\mathrm{r}=.276, \mathrm{p} .001)$, and it has been shown that there is a significant negative correlation with all. In previous studies, social support reports the most significant result of post-traumatic stress relief factors of firefighters [9][12][13]. Previous studies of domestic firefighting officers have reported that job satisfaction and stress coping are representative factors for relieving posttraumatic stress [20].

Firefighters are high-risk occupations and the prevalence of post-traumatic stress disorder is very serious [20], firefighters with severe post-traumatic stress symptoms reported depression and alcohol problems [21], depression was the most affected among the various stress factors that increased the level of post-traumatic stress disorder of firefighting officers [4]. The results of this study showed significant effects on post-traumatic stress in the order of feeling the need for counseling and treatment $(\beta=-.229, \mathrm{p}<.05)$, subjective health $(\beta=.210, \mathrm{p}<.05)$, and social 
support $(\beta=-.201, \mathrm{p}<.05)$. This shows that firefighters are realizing the necessity of counseling and treatment in relation to post-traumatic stress, and the more they feel unhealthy, the more stressful they are after trauma. Therefore, more professional and periodic counseling and treatment should be provided in relation to post-traumatic stress for firefighting officers, and social support for relieving stress of firefighting officers, that is, emotional, informational, material and evaluation support should be made.

\section{Conclusion}

This study was conducted to identify the social support of firefighting officers and the degree of post-traumatic stress, to identify factors affecting social support and post-traumatic stress, and to make a basic effort to improve the mental health of firefighting officers.

Based on this study, we would like to make the following suggestions.

First, it is necessary to study the counseling and treatment of experts who can experience continuous physical and mental stress and apply to firefighters who are frequently exposed to trauma cases

Second, follow-up studies on the relationship between post-traumatic stress and social support of firefighters are needed and research and attention are needed to apply for social support

Third, research and interest in the development and application of intervention programs to alleviate post-traumatic stress of firefighters are needed.

\section{References}

[1] Seo SW., "The effects of social support on the relaxation of fire fighters PTSD," Kyonggi University, pp.1-78, (2015)

[2] Park JB. and Cho SD., "The relationship between depression and post traumatic stress disorder among firefighters," Journal of the Korean Society of Hazard Mitigation, vol.13, no.5, pp.219-224, (2013)

[3] Kim SJ. and Kim, H., "Posttraumatic stress disorder: the aftermath of a shocking experience," Hakjisa, pp.1171, (2003)

[4] [4] Breslau N., Davis GC., Andreski P., and Peterson E. "Traumatic events and PTSD in an urban population of young adults," Archives of General Psychiatry, vol.48, no.3. pp.216-222, (1991)

[5] Kim SJ. and Cho GO., "The relationship among perceived social support, self-esteem and behavior problems of middle-school students," Theory and practice of education, vol.13, no.1, pp.361-385, (2002)

[6] Ursano RJ., Fullerton CS., and McCaughey BG., "Individual and community responses to trauma and disaster: the structure of human chaos," New York: Cambridge University Press, (1994)

[7] Oh SO., "Mediating effect of emotional regulation in the relationship between social support and subjective well - being," M.S. thesis, Korea University Graduate School of Education, pp.1-73, (2005)

[8] Park HS., Son CN., and Oh SW., "The effects of stress, social support, dysfunctional attitude and coping style upon depression,” Korean Journal of Clinical Psychology, vol.12 no.2, pp.425-437, (1993)

[9] Lee JY., Yoo JM., and Hyun MH., "The effects of emotional intelligence, active coping and social support on PTSD Symptoms of firefighters," Journal of Korean Psychology, vol.13, no.2, pp.373-389, (2008)

[10] Shinn, N., Lehmann, S., and Wong, N., "Social interaction and social support,” Journal of Social Issues, vol.40, no.4, pp.55-70, (1984)

[11] Lee, KN., "Elderly and social support,” Busan Women's University, vol.23, pp.303-346, (2001)

[12] Yoo JH., "(The) relations of PTSD symptoms, emotional states, coping style and social support in urban fire fighters,” M.S. thesis, Catholic University, pp.1-71, (2006) 
[13] Bae JM., "A study on the relationship between mobilization shocks, social supports, coping behaviors, and PTSD symptoms and psychological well-being of fire officials," Journal of the Korea government, vol.44, no.3, pp.141-163, (2010)

[14] Park JW., "A study on the development of social support scale," Ph.D. dissertation, Yonsei University, pp.1127, (1985)

[15] Horowitz, M., Wilner, N., and Alvarez, W., "Impact of dvent scale; a measure of subjective stress," Psychosom Medicine, vol.41, pp.209-218, (1979)

[16] Eun HJ., Gwon TW,, Lee SM., Kim TH., Choi ML, and Cho SJ., "A study on reliability and validity of the Korean version of impact of event scale-revised," Neuropsychiatric Medicine, vol.44, no.3, pp.303-310, (2005)

[17] Yug YS., "The effects of mindfulness based body-psychological exercise program on the reduction of posttraumatic stress (PTSD) symptoms in fire officials," Korean Journal of Sport Psychology, vol.29, no.4, pp.5773, (2018)

[18] Tedeschi, R. G., Calhoun, and L. G., "Posttraumatic growth: Conceptual foundations and empirical evidence," Psychological Inquiry, vol.15, no.1, pp.1-18, (2004)

[19] Shin HJ., "How empowerment and social support affect occupational stress of firefighters," Fire Science and engineering, vol.29, no.6, pp.139-146, (2015)

[20] Ryu JA,, Ha EH., Jeong-Choi KH., Kim JE., Park SW., and Kim HJ., "Firefighters and posttraumatic stress disorder," Korean J Biol Psychiatry, vol.24, no.1. pp.10-18, (2017)

[21] Lee HE., Kang JH., Yea BS., and Choi JH., "The effect of resilience on posttraumatic stress disorder symptoms and comorbid symptoms in firefighters," Anxiety and mood, vol.8, no.2, pp.86-92, (2012) 
Effects of Social Support on Post-Traumatic Stress of Firefighters

This page is empty by intention. 